\title{
Mulheres em Situação de Rua: Implicações Psicossociais de Estigmas e Preconceitos
}

\author{
Andréa Ferreira Lima Esmeraldo ${ }^{1}$ \\ ${ }^{1}$ Universidade Federal do Ceará, CE, Brasil.
}

\author{
Verônica Morais Ximenes ${ }^{1}$ \\ ${ }^{1}$ Universidade Federal do Ceará, CE, Brasil.
}

\begin{abstract}
Resumo: É cada vez maior o número de pessoas vivendo nas ruas, contudo, ainda são reduzidos os estudos e as políticas públicas voltados ao público feminino, razão pela qual este artigo focalizou o cotidiano das ruas objetivando analisar as implicações psicossociais dos estigmas e preconceitos na vida das mulheres em situação de rua. Ser mulher nesse cenário evoca relações de poder inseridas no conceito de gênero, considerado enquanto construção social e calcado em relações patriarcais. Estar nas ruas é estar exposta e ser alvo de ações discriminatórias que passam pela invisibilidade perante as políticas públicas, por processos de exclusão e por ações violentas perpetradas na rede de relações tecidas a partir da rua. Realizamos uma pesquisa qualitativa, na qual utilizamos entrevistas em profundidade com sete mulheres em situação de rua na cidade de Maracanaú (CE). O material coletado foi submetido à Análise de Conteúdo, que contou com apoio do software Atlas Ti 5.2 para identificar processos opressivos presentes nos estigmas e nos preconceitos, que atuam por meio de desqualificação e descrédito dessas mulheres e conduzem a sentimentos de humilhação e vergonha capazes de incidir sobre seus modos de vida e sobre as relações estabelecidas em seu cotidiano.
\end{abstract}

Palavras-chave: Mulheres, Pessoa em situação de rua, Opressão, Estigma, Preconceito.

\section{Homeless Women: Psychosocial Implications of Stigmas and Prejudices}

\begin{abstract}
The number of people living on the streets is increasing, yet studies and public policies aimed at the female public are still scarce, which is why this article turned to the daily life of the streets to analyze the psychosocial implications of stigmas and prejudices in homeless women's lives. Being a woman in this scenario evokes power relations inserted in the concept of gender, considered as a social construction and based on patriarchal relations. To be on the streets is to be exposed and to be the target of discriminatory actions that include invisibility in the face of public policies, processes of exclusion, and violent actions perpetrated in the network of relationships woven from the streets. We conducted qualitative research, in which we use in-depth interviews, with seven homeless women in the city of Maracanaú (Ceará, Brazil). We submitted the collected material to Content Analysis, which used the Atlas ti 5.2 software to identify oppressive processes present in the stigmas and prejudices, which act by disqualifying and discrediting these women and lead to feelings of humiliation and shame capable of affecting their ways of life and the relationships established in their daily lives.
\end{abstract}

Keywords: Women, Homeless, Oppression, Stigma, Prejudice. 


\title{
Mujeres en Situación de Calle: Implicaciones Psicosociales de Estigmas y Prejuicios
}

\begin{abstract}
Resumen: El número de personas que viven en las calles está aumentando cada vez más, pero aún se observan pocos estudios sobre el tema y escasas políticas públicas dirigidas al público femenino, por lo que este artículo ha recurrido a la vida cotidiana de las calles para analizar las implicaciones psicosociales de los estigmas y prejuicios en la vida de las mujeres en la calle. Ser mujer en este escenario evoca las relaciones de poder bajo el concepto de género, considerado como una construcción social y que se basa en las relaciones patriarcales. Estar en las calles es estar expuesta y ser objeto de acciones discriminatorias que pasan por la invisibilidad ante las políticas públicas, por procesos de exclusión y las acciones violentas perpetradas en la red de relaciones tejidas desde la calle. Se realizó una investigación cualitativa, en la cual se aplicaron entrevistas a profundidad con siete mujeres en situación de calle en la ciudad de Maracanaú (Ceará, Brasil). Se aplicó el análisis de contenido en el material, utilizando el software Atlas ti 5.2 para identificar los procesos opresivos presentes en estigmas y prejuicios, que actúan por medio de la descalificación y el descrédito de estas mujeres produciendo sentimientos de humillación y vergüenza capaces de incidir en sus formas de vida y las relaciones establecidas en su cotidiano.
\end{abstract}

Palabras clave: Mujeres, Personas en la calle, Opresión, Estigma, Prejuicio.

\section{Introdução}

Esta pesquisa se constituiu a partir da prática de uma das autoras como psicóloga atuante na política de assistência social num município da Região Metropolitana de Fortaleza, situação da qual se tornou premente a necessidade de fazer conhecer a realidade das mulheres cuja vida se organiza entre ruas, praças e calçadas. Nas cidades, sob viadutos e marquises ou nas praças, é significativa a quantidade de pessoas que tomam os ambientes públicos como espaço de moradia e vivem entre a invisibilidade e a produção de incômodo em quem passa pelo caminho. $\mathrm{O}$ signo que marca a moradia na rua é que necessidades básicas estão dispostas no espaço público, cenário em que se realiza atividades mais cotidianas, que MartínBaró (2017) nomeia como necessidades peremptórias de existência, dentre as quais cita atos como comer, dormir e proteção dos filhos.

No que se refere à rua como espaço de moradia e sobrevivência, C. M. M. Rosa, Bezerra e Vieira (1992) descrevem a pessoa em situação de rua, principalmente, como remanescente do processo produtivo, que tem inserções precárias no mercado de trabalho, o que a coloca na condição de sobrante e interpela outros campos da existência desses sujeitos. Já Escorel (1999) aborda a situação de rua a partir do conceito de exclusão social; ressalta que a ocorrência de pessoas vivendo nas ruas é a manifestação desse processo de exclusão e que ao realizar atividades da vida privada no espaço público tais sujeitos rompem com princípios de organização social que são demarcados nitidamente e opõem os espaços casa e rua.

Viver nas e das ruas é confrontar o mundo privado, expondo-o ao escrutínio público, e, em geral, busca-se fechar os olhos para tal realidade na tentativa de velar a própria existência das pessoas que pertencem a esse mundo. Quando tal realidade grita sua existência, passam a operar diversos modos de apartação, desde os mais sutis, que podem ser verificados a partir da negação de acesso a políticas públicas mais básicas, ações discriminatórias; ou modos mais explícitos e brutais, quando se desafia a própria existência do sujeito com violações do corpo que podem chegar até a morte. Pimentel, Santos, Nunes, Mendes e Silva (2015) analisaram um grande número de homicídios que vitimaram pessoas em situação de rua, para os quais não há solução ou comoção.

Longe de ser um amálgama indistinto, este grupo populacional é marcado pela heterogeneidade expressa no Decreto n. 7.053 (2009), que define como pessoas em situação de rua tanto aquelas que moram, como as que utilizam as ruas para sobrevivência, e 
têm a precariedade da moradia e a pobreza como marcadores primordiais. Delfin, Almeida e Imbrizi (2007) apontam como a Política Nacional para População em Situação de Rua faz referência à heterogeneidade como característica desse conjunto populacional, numa contradição ao tratamento recebido, que é entremeado pela homogeneidade que usurpa a singularidade e a história das pessoas e que conduz a um tratamento onde essa população é evitada, humilhada e violentada.

No universo das ruas, as mulheres formam o grupo de menor expressividade quantitativa, porém, esse grupo está envolto em um grande conjunto de opressões e suas vivências estão cercadas de invisibilidades, que tanto poderiam fazer supor um espaço de proteção frente aos olhares estigmatizados de maior parte da sociedade, quanto conduziriam a uma intangibilidade diante de políticas públicas e intervenções assistenciais das quais necessitam. Sarmento (2020) ressalta a inexistência de políticas públicas específicas para mulheres em situação de rua, à exceção de quando estão grávidas, circunstância na qual, muitas vezes, são dirigidas a elas ações punitivistas que culminam com a retirada de seus filhos. Já Bezerra (2018) destaca o papel protetivo da Assistência Social, que, todavia, não atende às particularidades dessas mulheres. Em pesquisa realizada em São Paulo, C. M. M. Rosa et al. (1992) identificaram, dentre o público investigado, um total de $90 \%$ de homens, enquanto a pesquisa oficial mais ampla, realizada pelo Ministério do Desenvolvimento Social e Combate à Fome (MDS, 2009), ratificou a predominância masculina: $82 \%$ do público pesquisado era composto de homens.

Para compreender as relações de gênero no contexto das ruas, recorremos à crítica às relações patriarcais enunciada por Saffioti (2015), que, ao utilizar o conceito de gênero como categoria de análise, enfatiza seu caráter histórico e indica que este não é capaz de explicitar as desigualdades entre homens e mulheres. Pontua a atualidade do conceito de patriarcado como um regime de exploração e dominação que homens exercem sobre as mulheres e que ordena as relações sociais, além de destacar os mecanismos que estabelecem padrões normativos calcados nas diferenças sociais e situam homens e mulheres na organização social. Biroli (2018) destaca, na noção de patriarcado, a estrutura de padrões que resultam em desvantagens para as mulheres, de modo que seu corpo, tempo e energia estão à disposição dos homens. Assim reconhecemos que este processo de dominação-opressão atinge de forma muito mais aguda as mulheres, em especial aquelas sobre as quais se conjugam, além da classe, o modo de vida que foge à expectativa da sociedade assentada em valores patriarcais.

A realidade vivida por mulheres em situação de rua e a forma como o cotidiano incide sobre sua existência colocando-as num determinado lugar social, revelam as estruturas sociais nas quais estamos todos inseridos e que nos impõem papéis singulares em sua organização. Como afirmam Marsicano e Levinson (2020), estruturas patriarcais estão organizadas produzindo controle, punição e violência para as mulheres não somente na relação com os homens, mas com outras mulheres em virtude de raça, sexualidade e classe, dentre outros marcadores. Nesse sentido, sobre as mulheres em situação de rua recai uma política que as mantém sob dominação.

A vida sob o manto do descrédito social conduz o modo de viver das mulheres em situação de rua. Assim, compreender que as vivências das mulheres se inserem num universo de opressões que marca as relações, modos de viver e papéis sociais, implica saber que estamos na trama de um sistema em que a vida está associada a um estado desumanizado que, para Guzzo (2016), ultrapassa as repercussões objetivas da escassez de recursos financeiros e revela implicações das condições subjetivas de um contexto econômico desfavorável. Ainda que não seja o único vetor, a pobreza marca a situação de rua por expor a classe oprimida à ausência de renda, assim como a uma estrutura ideológica que subalterniza as pessoas pobres. Accorssi e Scarparo (2016) afirmam que o descaso social marca a vida de pessoas que vivem em condição de pobreza e que elas estão submetidas a barreiras invisíveis que causam impacto tanto na própria identidade, quanto na forma de se relacionar com os outros. Esse é o cenário onde se localizam grupos que convivem com esquemas de marginalização que estão ancorados num modelo de dominação capaz de revelar processos psicossociais de opressão.

Parker (2015) aponta que o estigma, assim como o preconceito e a discriminação, são processos sociais vinculados a estruturas mais amplas de poder e dominação, que reproduzem e conservam as desigualdades sociais. Delfin et al. (2017) reconhecem que o estigma e o preconceito, enquanto crenças que distorcem a realidade, se constituem como processos 
que mantêm relações de exploração e dominação. Consequentemente, muito antes de qualquer contato com uma pessoa em situação de rua, um transeunte já tem uma imagem prévia desse sujeito que é mediada por esquemas tipificadores, que fazem emergir expectativas sobre o comportamento das pessoas que se encontram nessa situação, dos quais derivam determinados protocolos de interação. Dessa forma, os estigmas e preconceitos têm a prerrogativa consignar à população em situação de rua um lugar de descrédito veiculado por atitudes discriminatórias.

Segundo Goffman (2013), o estigma, efeito decorrente da interação social, é uma marca que distingue o sujeito ou grupo e que imprime atributos capazes de colocá-los em categorias que lhes conferem identidade social de caráter depreciativo, uma fraqueza ou uma desvantagem. $\mathrm{O}$ autor faz menção a três tipos diferentes de estigma relacionados a deformidades do corpo, culpas de caráter individual e aspectos religiosos e/ou raciais. Parker (2015) articula os processos de estigmatização e de discriminação com a produção de exclusão social e expande a perspectiva da marca distintiva para compreender o estigma nas relações sociais e de poder. Para Rondon Filho (2013), o estigma é capaz de criar um reconhecimento simbólico, por meio do qual as pessoas estigmatizadas e estereotipadas podem ser potencialmente vítimas de uma violência difusa.

O preconceito está associado a um juízo de valor direcionado a estas mesmas pessoas. Para Allport (1971), o preconceito constitui uma atitude de hostilidade a um grupo socialmente desvalorizado. Bandeira e Batista (2002) caracterizam o preconceito como um modo arbitrário de agir diante do que é diferente, mas que é marcado pelo valor negativo atribuído a esse outro e que lhe causa prejuízos, ou seja, depende de uma relação de poder. Desse modo, temse estabelecida uma forma violenta de relação com a diferença. Uma forma tão intensa de violação que as mortes de pessoas em situação de rua são detentoras de menor peso simbólico se comparadas às mortes das demais pessoas (Pimentel et al., 2015).

Tanto o estigma quanto o preconceito são materializados pela discriminação, que é a atitude excludente frente ao outro e se configura como o aspecto atitudinal do preconceito (Parker, 2015). A reflexão trazida por Moura Júnior, Ximenes e Sarriera (2013) evidencia que discriminação e preconceito têm como finalidade última a manutenção da ordem social; para tanto, utiliza-se o mecanismo de atribuir características negativas a determinados grupamentos, o que os diminui perante os demais grupos sociais; assim, descriminação e preconceito operam o processo de dominação-opressão. Link e Phelan (2001) apresentam o rebaixamento hierárquico de status como uma consequência dos estereótipos e acrescentam que o status socialmente desvalorizado conduz a desigualdades concretas nas interações dos grupos.

Carneiro (2011) observa que impera uma concepção de que há uma distinção que faz com que alguns seres humanos sejam considerados mais ou menos humanos que outros. Isso provoca a naturalização de desigualdades, pois a concepção prevalente no imaginário social de que há pessoas que carregam uma humanidade incompleta, justifica que lhes seja vedado o gozo pleno dos direitos humanos (Carneiro, 2011). Entre os componentes do estigma abordados por Link e Phelan (2001), a criação de um rótulo que diferencia e categoriza faz com que se acredite que a pessoa estigmatizada seja tão diferente que não seja considerada realmente humana.

Analisar a situação de rua sob esse prisma enseja a noção de que as relações sociais que se dão em decorrência do estigma e do preconceito hierarquizam as pessoas de maneira a veicular as expressões do classismo, racismo e patriarcado, dentre outras, e mitigam sua condição de humanidade, fazendo, por exemplo, com que a vida dessas pessoas tenha menos valor e sua perda tenha menos significância social. Donoso, Bastos, Faria e Costa (2013) ponderam que ser identificado como desnecessário, incômodo ou ameaçador cria permissividade para a eliminação dessas pessoas, seja de forma simbólica ou física. O processo de marginalização oriundo da estigmatização como detentor de um reconhecimento perverso de inferioridade, o que potencialmente funciona como justificativa para agressões às pessoas em situação de rua, é evidenciado por Moura Júnior et al. (2013).

A condição de pobreza carrega o peso de mecanismos opressores que promovem a construção de uma identidade estigmatizada de pobre que é perniciosa àquelas pessoas que a detêm, pois reduz as possibilidades de transformação dessa identidade (Moura Júnior \& Ximenes, 2016). Tal realidade faz com que nos questionemos sobre como os estigmas e preconceitos impactam o cotidiano das mulheres em situação de rua, razão pela qual objetivamos com este artigo analisar as implicações psicossociais dos estigmas e preconceitos na vida das mulheres em situação de rua. 


\section{Metodologia}

O cotidiano nas ruas precisaria ser acolhido por um desenho metodológico capaz de fazer emergir a vida dessas mulheres com base na compreensão de sua multiplicidade de vozes e sentidos. Diante disso, este estudo esteve, desde suas primeiras formulações, calcado na possibilidade de evidenciar a vida das mulheres em situação de rua e se constituiu não apenas no horizonte de revelar diferenças entre as experiências femininas e masculinas, mas de considerar o conjunto de opressões em que estão inseridas e apresentar suas vivências como singulares.

\section{Local da pesquisa}

A pesquisa foi desenvolvida em um município da Região Metropolitana de Fortaleza, com mais de 200 mil habitantes (IBGE, 2014), com uma feição urbana e industrial, característica que tem influência sobre o processo de composição da população em situação de rua. Pinto (2015) ressalta que a criação do Distrito Industrial operou um crescimento vertiginoso por meio de um processo de industrialização desordenado, que agregou os setores de comércio e serviços e se constituiu ao largo dos interesses da coletividade e do meio ambiente. Acrescenta que um fator de destaque na economia de Maracanaú é o entreposto da Central de Abastecimentos do Ceará S/A, que funciona desde os anos 1970 e que, até hoje, atrai pessoas dos mais diversos lugares em busca de oportunidades de trabalho e alimentação. A Central de Abastecimentos contribui com o fluxo de circulação de pessoas oriundas do interior do estado e sua localização nas proximidades de rodovias se reverte em grande movimentação de pessoas e transportes, além de gerar cerca de 10.000 trabalhos diretos. Por atrair pessoas em busca de trabalho e renda, essa instituição agrega em torno de si também algumas violações de direitos, dentre as quais é possível citar a vivência de rua.

O palco onde desenvolvemos este processo investigativo foi o Centro de Referência Especializado para População em Situação de Rua (Centro Pop), que é o único equipamento, dentre instituições públicas ou privadas de Maracanaú, destinado ao atendimento especializado à população em situação de rua. Desde 2012 oferta o Serviço Especializado para População em Situação de Rua, de natureza público-estatal, cujo objetivo é a realização de acompanhamento especializado a fim de facilitar o desenvolvimento de sociabilidades capazes de promover outras formas de vínculos na perspectiva de novos projetos ou trajetórias de vida. Articula as demais políticas setoriais para a promoção de direitos socioassistenciais, já que a falta de acesso a tais direitos contribui para intensificar os desafios próprios da vida nas ruas (MDS, 2011). Destacamos que essa unidade de atendimento não tem o objetivo de promover abrigamento para população em situação de rua. A escolha do Centro Pop como local para realização da pesquisa considerou o fato de ser a única unidade com serviços específicos para a população em situação de rua, além de uma das pesquisadoras atuar em sua coordenação, o que possibilitou acesso às participantes da pesquisa.

\section{Participantes da pesquisa}

O trabalho voltou-se a mulheres em situação de rua atendidas no Centro Pop de Maracanaú, maiores de 18 anos. Destacamos essa delimitação etária, pois tanto do ponto de vista normativo como o acesso a serviços e programas sociais são diferenciados para a população de crianças e adolescentes, o que justifica voltarmos nosso olhar para as mulheres adultas que vivem nas ruas. É relevante mencionar que o tempo de permanência nas ruas não foi utilizado como critério de inclusão, pois dado que as mulheres constituem um público reduzido tanto nas ruas como nos serviços públicos específicos, nossa intenção foi de poder nos aproximarmos de suas experiências, que apresentam peculiaridades e relevância desde o momento em que rompem com o ambiente da casa para adentrar no universo das ruas, de modo que a exposição às diversas violações a essas mulheres podem se expressar a despeito do tempo em que estejam nos espaços públicos.

As mulheres a quem destinamos o olhar são aquelas que moram na rua, em moradias extremamente precárias, ou que contingencialmente podem frequentar albergues e casas de passagem, mas que têm na rua a maior referência, e ainda àquelas que estejam em processo de saída das ruas. Tais vivências nos permitirão compreender os desafios e enfrentamentos necessários para garantir sua manutenção nesse cenário. Em comum, todas frequentaram o Centro Pop e lá foram convidadas a participar das entrevistas. Assim, de um total de 43 mulheres atendidas no Centro Pop, sete mulheres disponibilizaram-se a compartilhar suas experiências e, ao aceitarem, assinaram o Termo de Consentimento Livre Esclarecido. Ressaltamos o uso do critério de saturação para definição do total de entrevistadas. Na produção do trabalho, foram atribuídos nomes fictícios às entrevistadas. 
Tabela 1

Perfil das mulheres entrevistadas.

\begin{tabular}{lccc}
\hline Nome & Idade & Tempo na rua & Condição na rua \\
\hline Beth & 43 & 1 ano & Em processo de saída das ruas \\
Carmem & 44 & 1 ano e 2 meses & Em vivência de rua \\
Chiquinha & 34 & 1 ano e 3 meses & Em vivência de rua \\
Alcione & 37 & 5 anos & Moradia de rua \\
Tereza & 44 & Mais de 3 anos & Em processo de saída das ruas \\
Elza & 51 & 10 anos & Moradia de rua \\
Joana & 31 & 10 anos & Em processo de saída das ruas \\
\hline
\end{tabular}

\section{Construção e análise das informações}

Para a construção das informações utilizadas neste artigo, utilizamos abordagem qualitativa e recorremos a entrevistas em profundidade, como oportunidade para acessar o cotidiano dessas mulheres e seus atravessamentos; assim conseguimos alcançar a realidade de estigmas e preconceitos vividos pelas mulheres em situação de rua, bem como suas vicissitudes. Esta técnica, segundo Gaskell (2002), permite o surgimento de informações que contribuam para compreender as relações das pessoas investigadas com sua situação. Neste modelo de entrevista foi seguido um roteiro que priorizou 3 grandes categorias: a) modos de vida; b) estigmas e preconceitos; e c) modos de enfrentamento. Neste artigo nos deteremos sobre os aspectos que envolvem os estigmas e preconceitos vividos pelas mulheres em situação de rua. Por perceber que a temática que envolve experiências de estigmas e preconceitos tende a não ser imediatamente reconhecida por quem a vivencia, nos utilizamos da contação de uma pequena história como recurso de mediação, para que as entrevistadas opinassem sobre o que ouviram. Para a construção dessa história, foram considerados os fragmentos de acontecimentos que algumas mulheres apresentavam durante as atividades coletivas do Centro Pop e em relatos de experiências de pesquisas com mulheres em situação de rua. Essa estratégia foi bastante potente para a produção de narrativas, pois foi verificado um processo de identificação diante de uma situação concreta.

Todas as entrevistas foram realizadas no próprio Centro Pop, de forma individualizada e em ambiente fechado, para preservação do sigilo, e ocorreram no período de setembro a novembro de 2018. Utilizou-se o critério de saturação para definição da quantidade de entrevistadas.
As informações decorrentes desse processo investigativo foram gravadas e transcritas na íntegra; posteriormente, foram submetidas a procedimento de análise, que contou com o recurso tecnológico do software Atlas Ti 5.2. Utilizamos como técnica a Análise de Conteúdo, que é uma estratégia que tem na linguagem sua unidade interpretativa. As análises puderam identificar experiências de estigmas, preconceitos e discriminações que compõem os modos de vida destas mulheres.

\section{Aspectos éticos}

Consideramos importante apresentar algumas reflexões e inquietações sobre o lugar de pesquisadora neste processo investigativo, pois o contato com cada mulher e o feminino inscrito no campo discursivo das entrevistas fizeram visitar lugares de identificação e, ao mesmo tempo, de consciência das diferenças que nos distanciam e nos aproximam. Vigora a certeza de que o sistema capitalista cria abismos entre as experiências de vida das pessoas conjugando as estruturas opressivas de maneira singular em cada uma e, neste caso, temos a nitidez de que, mesmo na condição de mulher sujeita às assimetrias em função do gênero, ocupamos um lugar de privilégio diante dessas mulheres, já que os marcadores de raça e classe nos livram de uma série de violências e opressões vivenciadas cotidianamente por elas. Além de marcadores identitários distintos, não é possível desconsiderar a atuação como coordenadora do Centro Pop de Maracanaú, posição que pode ser considerada uma hierarquia na relação com as mulheres entrevistadas e foi ponderada em todo o processo de mobilização deste estudo, desde o convite a cada uma para a participação na entrevista, que procurou explicitar os objetivos e permitir que as convidadas pudessem se posicionar 
livremente sobre o desejo de fazer-se presente, o que ficou expresso na recusa de algumas convidadas.

Ressalto que as entrevistadas autorizaram sua participação por meio do Termo de Consentimento Livre Esclarecido e que o projeto da pesquisa que fundamenta este estudo foi submetido ao Comitê de Ética em Pesquisa da Universidade Federal do Ceará, em conformidade com a Resolução n. 510, de 07 de abril de 2016, do Conselho Nacional de Saúde, e aprovado sob C.A.A.E no 94848218.1 .0000 .5054 .

\section{Resultados e discussões}

A partir da escuta de mulheres entrevistadas, identificamos como estigmas e preconceitos articulam processos psicossociais de opressão presentes no cotidiano de mulheres em situação de rua e os apresentamos em três blocos de discussão. Inicialmente, enfocamos os estigmas e preconceitos como estratégia de dominação e opressão das maiorias populares voltada a manter interesses de grupos dominantes. Em seguida, problematizamos a relação dos estigmas com os processos que individualizam a situação de rua e usam a culpabilização como justificativa de opressão. Por fim, ressaltamos a ocorrência de sentimentos de vergonha e humilhação e o nexo com os estigmas. Essas categorias configuram implicações psicossociais dos estigmas e preconceitos na vida das mulheres em situação de rua a partir da realidade investigada. Para compreender esses processos, o trabalho foi orientado de forma a evidenciar o conceito de opressão que se situa na perspectiva da Psicologia da Libertação (Martin-Baró, 2017), como resultante de uma organização econômica, política e social que se sustenta no binômio dominação-opressão.

\section{Estigmas e preconceitos como estratégias de dominação-opressão}

Ser mulher nas sombras das ruas é se manter nas relações hierarquizadas, nas quais a extrema pobreza denota um valor social devido ao qual as mulheres são objetificadas e vivem na condição de menos valia. A ideia de que a mulher representa o sexo frágil ainda é comum num cotidiano no qual as relações baseadas no uso da força são muito presentes, percepção traduzida por Teresa (E5): "A mulher é mais frágil. A mulher é mais frágil, a mulher é mais indefesa. Porque homem sabe, né? Ele sabe se defender. E a mulher não". Sua visão reflete a ideia de que as diferenças de gênero são resultado de distinções na natureza de homens e mulheres, ou seja, ela lança mão de um discurso que tem bastante incidência na sociedade e incorpora essa ótica em sua narrativa. Bortoli (2017) argumenta que as mulheres em situação de rua percebem diferenças entre as experiências masculinas e femininas na rua, realidade que atribuem à maior fragilidade física das mulheres. Desse modo, a ideia de fragilidade está ancorada no olhar discriminatório e estigmatizado que a sociedade dirige às mulheres.

A vivência num contexto de opressão marca o que cada pessoa é e como lida com essa realidade. Embora componha um público reduzido comparativamente aos homens, as mulheres que vivem em situação de rua estão submetidas, em geral, às dificuldades enfrentadas por toda população em situação de rua, porém, ao vivenciarem a rua sendo mulher, o gênero se constitui em agravante que potencializa riscos inerentes a esse espaço. Esta é a percepção algumas das mulheres entrevistadas:

A vida na rua pra mulher, é mais melhor pra homi do que pra mulher, porque pra mulher é difícil, principalmente eu que não tinha familiar, nera?! Era só, sozinha, não tinha família, não tinha ninguém, era mais ruim. Tinha muita gente que tinha os familiar, que vinha chamar, resgatar da rua, chamar pra ir pra casa, e eu, era mais triste. A minha vida era uma tristeza tão grande, hoje eu fico triste, às vezes quando num tem nada em casa eu fico triste (Joana, E7).

Mesmo que, numa resposta mais direta, algumas afirmem que a rua é um lugar difícil para homens e mulheres, elas reconhecem que o gênero é um componente de complexificação, que agrega inconvenientes para as mulheres, sobretudo para aquelas que estão sozinhas, como no caso de Joana. Biroli (2018) evidencia como as relações pautadas no gênero são produzidas a partir de dinâmicas de opressão, que envolvem a determinação do lugar das mulheres na sociedade. A autora argumenta que as hierarquias de gênero intensificam desvantagens para as mulheres, para quem a vida doméstica é o destino. Na compreensão de Sicari e Zanella (2018), a rua é um lugar que reproduz um modelo patriarcal.

Ao demonstrar que interesses de classe operam processos de dominação e opressão, é necessário dar relevo a outras manifestações opressivas que se 
configuram em razão de marcadores sociais específicos. Mayorga (2014) mostra que este sistema de opressões atinge diferentemente grupos de pessoas em razão do gênero, etnia e raça, orientação sexual, identidade de gênero, territorialidade e modos de vida. As mulheres em situação de rua estão inseridas nesses contextos opressivos conjugando facetas diferentes desse processo. As vivências mediadas pela classe social e pela condição de pobreza impactam na trajetória que as conduz a uma vida cercada de incertezas presentes na rua, mas a condição de ser mulher e de assumir um modo de vida que desafia a perspectiva tradicional de família, faz com que as formas de opressão se amplifiquem em seu cotidiano e, de acordo com A. S. Rosa e Brêtas (2015), expõe as mulheres em situação de rua a uma série de violências que operam nos campos físico e simbólico.

Muitas vezes, no dia a dia das ruas, a marca da cultura de dominação se apresenta em comportamentos que, de um lado, evidenciam a conformação com a vivência de processos opressivos, de modo que há uma espécie de naturalização do tratamento recebido em função do contato com pessoas que não vivem as ruas; e de outro lado configuram reproduções de comportamentos opressores. Vale destacar o relato de Carmem:

Pesquisadora: Então ele acha que os clientes vão se sentir incomodados [com a presença de pessoas em situação de rua]?

Carmem: Realmente é mesmo, né? A gente vamo passando, já ficam... tem uns que se levantam, ficam com medo, e realmente, muita violência e tem muitas pessoas morador de rua que roubam. Não sabem que a gente não rouba, mas na mente dele, por causa dos outro, a gente paga, né? (Carmem, E2).

O diálogo acerca da relação com os comerciantes traz à tona a incorporação, por parte da entrevistada, de um discurso que marginaliza e desqualifica a população em situação de rua ao corroborar a imagem das pessoas que vivem nas ruas como violentas ou ameaçadoras. Pinto (2015) argumenta que no atual contexto socioeconômico, evidenciam-se processos sociais de individualização, que se refletem em culpabilização da pobreza e na delegação dos problemas para cada pessoa, eximindo a complexidade de seu enfrentamento.
Os processos de opressão podem ser manifestos por uma certa descrença das mulheres em si mesmas e uma visão de imutabilidade da realidade, que conduz à aceitação de seu destino e revela um certo ceticismo quanto às possibilidades de sair da situação de rua, pois elas não se veem em condições de, por meios próprios, fazer um movimento para isso. Assim, elas concluem que, diante da realidade vivida, apenas Deus pode contribuir para alguma mudança, o que mostra que a resolução desse problema é delegada a um terceiro e revela elementos da ideologia de submissão e resignação. Não há, por parte das entrevistadas, a percepção de que fatores conduzem à vida na rua, tampouco dos elementos que potencializariam alguma mudança.

Pesquisadora: E... quais os problemas mais comuns do seu dia a dia?

Alcione: É esse sofrimento da rua. Eu choro, peço a Deus pra me ajudar pra sair dessa rua, mas eu não consigo sair mais. Não consigo. Uma que eu vendi minha casinha que Deus me deu, e minha família não me aceita mais em casa, devido deu ter usado, ser a usuária de droga e tá nessa vida de bebedeira. Minha família tem vergonha de mim (Alcione, E4).

O diálogo com Alcione revela o processo de internalização do que Góis (2003) apresentou como uma ideologia de submissão e resignação, segundo a qual a estrutura de classes, por sua organização autoritária e massacrante, tende a uma tensão social exacerbada, que exige controle. Segundo essa perspectiva, a vivência em condição de pobreza e de opressões inscritas nas condições de vida da população, sustenta a descrença e a percepção de imutabilidade da realidade vivida, bem como a aceitação do destino. Essa ideologia se revela no comportamento das classes dominantes e repercute nos processos de isolamento e na busca de soluções individualizantes para os problemas cotidianos vividos pelos oprimidos. Nesse modelo, as classes subalternizadas são postas numa condição de inferiorização cultural, social e econômica.

Ao internalizar a submissão e a resignação, a classe oprimida passa a delegar a terceiros a resolução de seus problemas. Esta concepção coaduna com o conceito de fatalismo, ou seja, a noção de que há uma predeterminação relativa à existência humana, um destino 
inescapável que limita os seres humanos, aos quais incumbe acatar e se submeter a tal sorte. Os traços do fatalismo não são absolutos, isto é, a pessoa tem formas diversas de se relacionar com o cotidiano e isso contribui para que processem movimentos de resistência; ademais, cabe ressaltar que os traços fatalistas estão relacionados às condições político-culturais e econômicas do sistema social de cada lugar. Cidade (2012) estabelece uma relação entre as condições de pobreza e seus impactos nos modos de vida das pessoas, que diante de uma realidade desfavorável assumem uma postura de resignação e descrença.

Uma das características apontadas por MartínBaró (2017) como constructo ideacional do fatalismo diz respeito à convicção de que o destino é inevitável, o que corresponde a perceber que há um destino fatal e imutável. Essa imutabilidade da situação se reverte em impotência das mulheres para sair da condição de rua, de modo que suas experiências cotidianas confirmam essa sensação de incapacidade e fazem com que haja uma tendência em aceitar a realidade dada.

Joana denota a resignação como condição para viver seu dia a dia:

Hoje em dia, lá em casa não tem alimento, hoje eu bebi café na vizinha, conversando mais ela. "Joana, num tem nada pra lhe dar hoje" tem nada não, mulher, meno um cafezim, bebi e vim pra cá. Ele já vinha de quebrada, aí eu disse: tu vai pra onde? Pois eu vou mais tu, viemo caminhando tem nada não. Rapaz eu achei ... agradeço a Deus paguei o aluguel, paguei os papel de energia, paguei os papel de água, paguei a muié 250, paguei as coisa direitinho, pra mim sobrando um real, eu se viro. Deus vai me ajudar e vai abençoar. Peço ao menos pra Deus tocar no coração e me ajudar, comprar um quilo de arroz, um quilo de feijão pra botar no fogo. Tenho fogareiro porque fogão eu num tenho, fogão a gás eu num tenho, nem bujão. Mas nem isso eu tinha! Eu morava na lona, não tinha nada, só uns mulambo véi. As roupa veia tudo fedendo, não tinha nada (Joana, E7).

Num cotidiano marcado por inúmeras privações, o que se vive é uma prevalência do tempo presente, de modo que o sonho e a esperança de sua realização precisam contar com a delegação a um ente superior, já que as condições materiais e históricas parecem não ser suficientes para se antever um futuro melhor.
Moura Júnior e Ximenes (2016) identificam a pobreza como uma prática de opressão, que causa prejuízos na vida dos indivíduos na medida em que os posiciona num lugar de inferioridade perante os demais, capaz de produzir um comportamento de passividade e de violência que repercute em aspectos de saúde e bem-estar dessas pessoas.

O contexto opressivo em que vivem as mulheres em situação de rua faz com que tenham que lidar com expressões muito específicas do universo em que estão colocadas na sociedade e, nesta perspectiva, o encontro com outros modos de vida faz emergir atitudes reveladoras de estigmas e preconceitos. Essa imagem de descrédito e de menos valia de quem vive na rua é incorporada pelas pessoas que estão fora desse contexto: "Porque o preconceito é com nós tudinho, a humilhação, às vezes empurram a gente: 'sai daqui bando de bebo véi, drogueiro'. É nós todos que passa por isso" (Carmem, E2). Essa fala indica que os processos de opressão conduzem a uma exclusão em que os estigmas e preconceitos funcionam na divisão entre as pessoas que pertencem a determinado mundo e as que estão em outro, mas o agravante é que, com a marca do descrédito, a desqualificação torna-se permitida. Sob esse prisma, aqueles que assumem o papel de superioridade assumem a permissão para desqualificar aquelas que estão na condição de destituídas de direitos.

\section{Estigma e culpabilização}

A concepção de que as mulheres em situação de rua são responsáveis por sua condição tem relação com a ideia de culpa de caráter individual expressa por Goffman (2013). Carmem (E2) relata o que pensa acerca das mulheres que vivem na rua:

Na minha opinião é o... tá certo não, tem que lutar pra conseguir o seu objetivo, né? Porque como eles trabalha pra lutar, a gente tem que também... porque tem muita gente que tem famía, é só butar a cabeça pra funcionar, porque curtir, curte só o final de semana, como eu faço. Só final de semana, na semana é atrás de faxina, atrás de cuidar de idoso. Atrás de trabalho, mas eles não querem nada, eles querem ficar... E tá aí, tá tudo lá bebendo, eu não bebo não, não tem quem faça. Bebi aquele dia que eu cheguei porque eu fui ver ela e ele não deixou, de manhã cedo. 
Nessa narrativa está presente a ideia de que a pessoa é a responsável pela vivência na rua e o movimento para sair dessa situação é uma escolha pessoal, o que desconsidera fatores de ordem econômica e social. A lógica da culpa é evidenciada por Schilling e Miyashiro (2008), para quem o conceito de estigma indica uma fraqueza moral da pessoa portadora desse estigma. É possível depreender dos discursos produzidos sobre essa população um reforço acerca da ideia de fraqueza moral, ideia incorporada pela própria pessoa em situação de rua.

Para Pinto (2015), as pessoas em situação de rua expressam em suas histórias a baixa autoestima, o isolamento e a falta de expectativas como decorrentes do preconceito que vivenciam. Tereza (E5) exprime bem como a relação com a comunidade, mediada por discriminações, é capaz de produzir sofrimento:

Com sofrimento, eu sofria por dentro. Porque eu não sou de... de desabafar com ninguém. Só quero guardar pra mim e isso me adoece... Somente isso mesmo... Não confiava em ninguém. Em ninguém! Ninguém pra mim, é ninguém não era de confiança. Só confiava em Deus, somente nele mesmo (Tereza, E5).

A discriminação e a estigmatização incidem sobre determinadas coletividades de modo a criar um cenário de subordinação cultural, política e socioeconômica a um determinado grupo dominante. Rondon Filho (2013) explica que as minorias sociais são constituídas por aqueles que, independente do quantitativo numérico em relação ao grupo dominante, estão na condição de minoria em razão de uma lógica de inferiorização e estigmatização. Além disso, o autor acentua que é por meio do estigma do outro que se sustenta o status de normalidade de um sujeito ou grupo. Assim, os atos que mantêm a população em situação de rua na condição de inferioridade podem ser apreciados como atos opressivos que ampliam as diferenças sociais e marcam os processos de dominação.

Ao se rechaçar a presença das pessoas em situação de rua, tem-se configurada a impossibilidade decorrente do pertencimento a um grupo socialmente desvalorizado; isso revela a constituição de barreiras a necessidades vitais de cada ser humano. Chiquinha (E3) expõe como a relação de sociabilidade é permeada pela desvalorização: "Me chamava de piranha, dizia que eu tava ali por tá, me julgava, me chamava de mulher de programa, dizia que... que eu... jogava pedra, passava as coisa na minha cara, né?" (Chiquinha, E3). Rodrigues, Lima e Holanda (2018) destacam que as pessoas em situação de rua são vinculadas a valorações pejorativas que as identificam como violentas e criminosas. A constatação de que as pessoas se sentem legitimadas a proferir xingamentos e desferir atos de agressividade a uma pessoa pelo simples fato de estar na rua, expressa a hierarquia que se estabelece nas relações sociais fundadas em esquemas discriminatórios.

No caso das mulheres, verifica-se que essa estigmatização cruza os referenciais da pobreza e do feminino, de modo que a exposição de suas vidas as fragiliza. Além da fragilização, há um processo de massificação das pessoas em situação de rua, que apaga suas individualidades. Delfin, Almeida e Imbrizi (2017) afirmam que a população em situação de rua sofre um processo de homogeneização que esvazia sua singularidade e sua história, algo que se apresenta também na percepção de Elza (E6): "Ninguém quer respeitar a gente, ninguém. Pensa que todo mundo é igual, é marginal. Não, todo mundo marginal não". A visão que se tem da pessoa em situação de rua demonstra que, de modo geral, todas as pessoas são igualadas numa mesma categoria, a de sujeitos marginais ou fora da lei, desconsiderando a singularidade de cada homem ou mulher que está na rua.

No caso da população em situação de rua agregam-se diversos estereótipos negativos a essa condição, pois ao se identificar que uma pessoa vive e sobrevive das ruas, engendra-se sentidos que ultrapassam o local de moradia e outros atributos lhe são conferidos, como o da drogadição, da marginalidade e, no caso das mulheres, de que fizeram algo errado para terem que sair de casa. Carmem (E2) ilustra esta ideia: "Somo muito discriminado, né?! Vai pedir alimentação, alguma coisa, diz que a gente vai vender por droga, às vez dá alimento, dá roupa, mas diz que 'é, vocês vão trocar por droga'”. Assim, há dois processos que se entrelaçam: a redução do sujeito ao atributo estigmatizante e a responsabilização individual pelo estigma. A responsabilidade pela condição de rua e pelas possibilidades de sair dessa condição é imputada a essa população, desconsiderando os processos de exclusão que são vivenciados pela sociedade.

Há uma ideia de que atributos negativos prevalecem quando se faz referência às pessoas que vivem nas ruas e, para compreender esse processo, 
recorremos a Ferreira, Silveira, Noto e Ronzani (2014), para quem o estigma internalizado indica a concordância com o preconceito que é dirigido a membros de um subgrupo e faz com que passem a adotar atitudes negativas contra si, o que afeta a qualidade de vida das pessoas. Essa perspectiva é muito comum em determinados grupos, como o das as mulheres em situação de rua, que por vezes adotam o estigma como legítimo e o reforçam entre seus pares ou se colocam em situação de inferioridade perante aqueles que estão fora do grupo. Portanto, é possível compreender que os estigmas e preconceitos se organizam de modo a transcender aqueles que os exprimem e podem, tal qual ocorre com outros processos opressivos, ser assumidos mesmo pelas pessoas que estão na condição de alvos desses fenômenos. A situação de rua vista individualmente coloca sobre a pessoa que está na rua a culpa, a responsabilidade por esta vivência, pelos percalços intrínsecos a tal condição e pela possibilidade de saída das ruas.

Relações de poder hierarquizadas são veículos para a produção e cristalização dos estigmas e mantenedores de processos excludentes, que decorrem da classificação social em que as pessoas estigmatizadas são colocadas. Parker (2015) afirma que tanto o estigma quanto a discriminação devem ser compreendidos por meio de estruturas amplas de poder e dominação. Em seus estudos, considera a centralidade do estigma na produção e reprodução de estruturas de poder que se sustentam em controle de sistemas sociais e mantêm desigualdades hierárquicas nas quais alguns grupos são desvalorizados e outros conservam o status de superioridade.

\section{Vergonha e humilhação}

Uma das consequências do estigma e do preconceito na vida de um sujeito que sofre ações discriminatórias, são as experiências que evocam práticas de humilhação capazes de fomentar sentimento de vergonha. $\mathrm{O}$ reconhecimento de que existem pessoas marcadas pela menos valia e pela subalternidade é capaz de fundamentar essas práticas de humilhação. Esse sentimento se manifesta diante de situações em que os estigmas e julgamentos morais as colocavam em situação de discriminação.

Pesquisadora: Eu vou contar aqui uma história e você vai me falar o que que você pensa dela. Tá?
É... É a história de uma mulher chamada Graça, que ela mora na rua, ela tem 33 anos, e na rua ela vive só. Ela trabalha com reciclagem e dorme no centro, perto de uma farmácia. A Graça reclama que as pessoas, quando ela está dormindo na rua, as pessoas passam e não notam que ela tá lá. Outras vezes, Graça reclama que as pessoas só notam quando é pra mexer com ela. O que é que cê acha dessa história?

Carmem: Isso é humilhação, né? Pra gente que tá ali, né? Porque a gente já tá passando uma crise ruim, né? E ainda fazer isso com a gente. É uma dor que a gente fica na mente, será que um dia eles não vão passar por isso? O mundo dá muitas volta. E um dia ela está ali, um dia ela vai tá na casa dela, linda e maravilhosa, que nada pra Deus é impossivel, né? E um dia eles vão tá lá, com a mesma situação dela, e ela vai ter pra dar a eles. Eu penso assim, que um dia eles vão vencer, assim, tem que querer, como eu. Eu quero isso pra mim, não quero essa vida (Carmem, E2).

Essa história contada a Carmem também foi narrada para cada uma das mulheres entrevistadas e, diante dela, assim Alcione reagiu:

Parecida com a minha. A gente que mora na rua, a gente é muito humilhado. Tanto a mulher como o homem. Tem gente, passa por a pessoa faz de conta que tá vendo um lixo, faz de conta que tá vendo um cachorro. Tem deles que acospe, cospe quando vê a gente. Quando a gente vai pedir uma ajuda, manda logo a gente sair de perto. Pra mim eles pensa, é com nojo da gente que mora na rua com medo da gente assaltar. A rua divía, essa vida de rua, é homilhada menos... (Alcione, E4).

Alencar e La Taille (2007) afirmam que no cotidiano há várias maneiras de práticas de humilhação atingirem uma pessoa e, para compreender o conceito, fazem alusão à definição de respeito como o reconhecimento de que alguém é dotado de direitos e possui uma dignidade intrínseca, dessa forma, articulam a humilhação como seu oposto. A humilhação é um ato ou evento externo, capaz de provocar a diminuição da dignidade e do orgulho, e a desigualdade nas relações de poder, de modo que há uma diminuição ou uma degradação da identidade de alguém, 
ou seja, a humilhação é um fenômeno complexo que ocorre numa relação (Zavaleta, 2007).

A representação do que é considerado humilhação nos trechos apresentados, mostra a discordância de Carmem e Alcione com a prática de humilhação. Revela ainda que há uma divisão entre "nós" - as pessoas que sofrem esse processo - e "eles" - o grupo de pessoas que por não estarem na condição de rua assumem um lugar de superioridade e sentem-se legitimadas a cometer as práticas discriminatórias que culminam em humilhação. Spiassi (2016) adverte que para as mulheres em situação de rua a humilhação é mais contundente, já que elas se percebem numa relação de maior desvantagem, pois elas estariam em inferioridade não só diante do coletivo da sociedade, como também do próprio grupo de pessoas em situação de rua.

Questionadas sobre como se sentiam frente à discriminação, Chiquinha e Tereza se posicionam:

Muito mal, né? Chorava muito, eu. Chorava demais, demais , demais, demais. E aquela palavra, assim, aquela palavra era uma palavra tão dolorosa que eu não... não aguentava. Eu não aguento, eu não sei aguentar as coisa dos outro e, assim, responder a pessoa (Chiquinha, E3).

Eu chorava. Eu chorava, chorava mesmo. Chorava que às vezes, assim, até, assim, deu perguntar alguma coisa pra uma pessoa e a pessoa não me responder, e eu às vezes ficava revoltada e dizia: "Tu já olhou pra dentro da tua casa? Tu já olhou pra onde é que teu filho vai? Se ele vai mesmo pra escola? Se ele anda com boas amizade? Vai ver não, né?". Era isso que, às vezes, eu respondia pras pessoas que me desprezavam (Tereza, E5).

As narrativas apresentadas estão carregadas de afeto, de modo que traduzem o impacto da vivência de humilhação na vida dessas mulheres, um desmerecimento que paralisa Chiquinha e que enseja em Tereza o sentimento de revolta. Embora seja um fenômeno social que opera no campo das relações, a humilhação é apresentada por Carmem (E2) como uma vivência pessoal, única: "Porque o preconceito é com nós tudinho, a humilhação, às vezes empurram a gente: 'Sai daqui, bando de bebo véi, drogueiro'. É nós todos que passa por isso. Só quem entende mesmo a gente é quem já passou, por isso, né?". Essa percepção contribui para se assimilar as diferentes formas de reação que se manifestam numa situação de humilhação. Zavaleta (2007) pontua que a humilhação, assim como a vergonha, tem inúmeras repercussões no bem-estar psicológico, e ressalta que na vergonha impera uma ideia de não corresponder aos próprios padrões; expressa, pois, um caráter individualista. E como tal, Moura Júnior (2015) alerta que o sentimento de vergonha pode advir mesmo que não esteja associado a uma situação real. Assim, neste ponto reside uma grande diferença entre humilhação e vergonha, pois enquanto o sentimento de vergonha se dá pela apropriação do valor negativo ou depreciativo, na humilhação, o ato de rebaixamento é tido como injusto.

Contudo, ainda que as opressões engendradas e mantidas culturalmente por processos estigmatizantes ensejem os sentimentos de vergonha e humilhação com grande repercussão na forma como estas mulheres conduzem seus modos de vida, emerge a necessidade de reconhecer cada uma das mulheres como sujeitos de possibilidades e ponderar sobre os processos de resistência empreendidos por elas.

\section{Considerações finais}

Para analisar as implicações psicossociais dos estigmas e preconceitos na vida das mulheres em situação de rua, foi necessário perceber estruturas opressivas que sustentam padrões de dominação complexos que não se colocam apenas nas relações de classe social, pois estendem-se para os diversos grupos de interação dessas mulheres. Essas mesmas estruturas que são constitutivas e fundamentam a existência dos estigmas e dos preconceitos, são materializadas por meio de práticas discriminatórias dirigidas a essas mulheres.

A relação entre visibilidade e invisibilidade na vida das mulheres em situação de rua é mediada pelos interesses e agentes locais, ora sendo evidenciada sua presença pela estranheza, ora ocultada, mas incluída no quesito da menos valia: essas mulheres reproduziram falas segundo as quais foram postas num lugar que está fora do humano. Ademais, muitas vezes incorporaram o descrédito desse lugar, que se associa ao fatalismo. Enquanto processo psicossocial, a resolução de seus problemas cotidianos está relacionada com a impossibilidade de mudança por meios próprios. Puderam exprimir sentimentos de humilhação e vergonha que estavam relacionados à 
discriminação sofrida e que marca tanto mais o corpo que o cotidiano.

Ao nos debruçarmos sobre os estigmas e preconceitos que atingem as mulheres em situação de rua, contribuímos para evidenciar como relações de opressão atingem-nas e as expõem a situações de violência e violações de direitos básicos. Também se revelou o quanto esses estigmas e preconceitos têm capacidade de serem incorporados pelas mulheres e, em determinada medida, afetarem de forma contundente suas relações e seu cotidiano.
Este estudo se concentrou na realidade vivida por mulheres cisgênero, o que se deveu à realidade de mulheres inseridas nas atividades vinculadas ao Centro Pop de Maracanaú, todavia, seria importante ampliar o horizonte da pesquisa para abranger mulheres trans, visto que os estigmas e preconceitos podem ser atravessados por sua identidade de gênero. $\mathrm{O}$ acesso a mulheres que não acessam qualquer política pública poderá se constituir como qualificação do campo da pesquisa com mulheres em situação de rua.

\section{Referências}

Accorssi, A., Scarparo, H. (2016) Representações sociais da pobreza. In V. M. Ximenes , B. B. Nepomuceno, E. C. Cidade \& J. F. Moura Júnior (Orgs.), Implicações psicossociais da pobreza: Diversidades e resistências (pp. 67-94). Expressão Gráfica e Editora.

Alencar, H. M., La Taille, Y. (2007). Humilhação: O desrespeito no rebaixamento moral. Arquivos Brasileiros de Psicologia, 59(2), 217-231.http://pepsic.bvsalud.org/scielo.php?script=sci_arttext\&pid=S1809-52672007000200011

Allport, G. W. (1971). La naturaleza del prejuicio (4a ed.). Editorial Universitaria de Buenos Aires.

Bandeira, L., \& Batista, A. S. (2002). Preconceito e discriminações como expressões da violência. Revista Estudos Feministas, 10(1), 119-141. https://doi.org/10.1590/S0104-026X2002000100007

Bezerra, F. S. (2018). "Nos bares, na lama, nos lares, na cama: Uma análise ontológica da violência contra a mulher em situação de rua no Brasil contemporâneo [Dissertação de mestrado, Universidade Federal do Rio Grande do Norte]. https://repositorio.ufrn.br/jspui/handle/123456789/27248

Biroli, F. (2018). Divisão sexual do trabalho. In Gênero e desigualdades: Os limites da democracia no Brasil. Boitempo.

Bortoli, S. R. (2017). Mulheres adultas em situação de rua e a mídia: Histórias de vida, práticas profissionais com a população de rua e representações jornalísticas [Tese de doutorado, Escola de Comunicações e Arte, Universidade de São Paulo].

Carneiro, S. (2011). Racismo, sexismo e desigualdade no Brasil. Selo Negro.

Cidade, E. C. (2012). Juventude em condições de pobreza, modos de vida e fatalismo. [Dissertação de Mestrado, Universidade Federal do Ceará].

Decreto n. 7.053, de 23 de dezembro de 2009. (24 dez. 2009). Institui a Política Nacional para a População em Situação de Rua e seu Comitê Intersetorial de Acompanhamento e Monitoramento, e dá outras providências. Diário Oficial da União, pp. 16-17. http://www.planalto.gov.br/ccivil_03/_ato2007-2010/2009/decreto/d7053.htm

Delfin, L., Almeida, L. A. M., \& Imbrizi, J. M. (2017) A rua como palco: Arte e (in)visibilidade social. Psicologia e Sociedade, 29, 1-10. https://doi.org/10.1590/1807-0310/2017v29158583

Donoso, M. T. V., Bastos, M. A. R., Faria, C. R., \& Costa, A. A. (2013). Estudo etnográfico sobre pessoas em situação de rua em um grande centro urbano. Revista Mineira de Enfermagem, 17(4), 894-901. https://doi. org/10.5935/1415-2762.20130065

Escorel, S. (1999). Vidas ao léu: Trajetórias de exclusão social. Editora Fiocruz.

Ferreira, G. C. L., Silveira, P. S., Noto, A. R., \& Ronzani, T. M. (2014). Implicações da relação estigma internalizado e suporte social para saúde: Uma revisão sistemática da literatura. Estudos de Psicologia, 19(1), 77-86. https://doi. org/10.1590/S1413-294X2014000100010

Gaskell, G. (2002). Entrevistas individuais e grupos. In M. Bauer \& G. Gaskell (Orgs.), Pesquisa qualitativa com texto, imagem e som: Um manual prático (pp. 39-63). Vozes.

Goffman, E. (2013). Estigma: Notas sobre a manipulação da identidade deteriorada (4a ed.). LTC. 
Góis, C. W. L. (2003). Por uma psicologia popular. In C. Gois, Psicologia comunitária no Ceará: Uma caminhada (pp. 35-70). Publicações Instituto Paulo Freire de Estudos Psicossociais.

Guzzo, R. S. L. A. (2016). A (des)igualdade social e a psicologia: Uma perspectiva para o debate sobre a pobreza. In V. M. Ximenes, B. B. Nepomuceno, E. C. Cidade \& J. F. Moura Júnior (Orgs.), Implicações psicossociais da pobreza: Diversidades e resistências (pp. 149-164). Expressão Gráfica e Editora.

Instituto Brasileiro de Geografia e Estatística. (2014). Sínteses de indicadores sociais: Uma análise das condições de vida da população brasileira. Estudos \& Pesquisas, (34).

Link, B. G., \& Phelan, J. C. (2001) Conceptualizing stigma. Annual Review of Sociology, 27. https://doi.org/10.1146/ annurev.soc.27.1.363

Marsicano, A. C., \& Levinson, E. (2020). Mulheres e as ruas: O debate sobre gênero atravessado pela classe. In I. Rodrigues \& D. C. Fernandes, Cidadãos em situação de rua: Dossiê Brasil-grandes cidades (pp. 93-112). CRV Editora.

Martín-Baró, I. (2017). Crítica e libertação na psicologia: Estudos psicossociais. (F. Lacerda Jr., Trad.). Vozes.

Mayorga, C. (2014). Algumas contribuições do feminismo à psicologia social comunitária. Athenea Digital, 14(1), 221-236. https://doi.org/10.5565/rev/athenead/v14n1.1089

Ministério do Desenvolvimento Social e Combate à Fome. (2009). I Censo e Pesquisa Nacional sobre a população em situação de Rua - Síntese de resultados. In Ministério do Desenvolvimento Social e Combate à Fome, Rua: Aprendendo a contar: Pesquisa nacional sobre a população em situação de Rua (pp. 85-110).

Ministério do Desenvolvimento Social e Combate à Fome. (2011). Orientações sobre o Centro de Referência Especializado para População em Situação de Rua e Serviço Especializado para Pessoas em Situação de Rua. https://www.mds.gov.br/webarquivos/publicacao/assistencia_social/Cadernos/orientacoes_centro_pop.pdf

Moura Júnior, J. F., \& Ximenes, V. M. (2016). A identidade social estigmatizada de pobre: Uma constituição opressora. Fractal: Revista de Psicologia, 28(1), 76-83. https://doi.org/10.1590/1984-0292/1051

Moura Júnior, J. F., Ximenes, V. M., \& Sarriera, J. C. (2013). Práticas de discriminação às pessoas em situação de rua: Histórias de vergonha, de humilhação e de violência em Fortaleza, Brasil. Revista de Psicología, 22(2), 18-28. https://doi.org/10.5354/0719-0581.2013.30850

Parker, R. (2015). Interseções entre estigma, preconceito e discriminação na saúde pública mundial. In S. Monteiro \&W. Villela, Estigma e saúde (pp. 25-46). Editora Fiocruz.

Pimentel, E., Santos, H. M., Nunes, A. C. O., Mendes, A. K. S., \& Silva, J. S. (2015). Mortes invisíveis: Um estudo sobre homicídios de moradores de rua em Maceió. Configurações, 16, 41-54. https://doi.org/10.4000/ configuracoes. 2840

Pinto, R. M. P. (2015). Fenômeno população em situação de rua à luz da questão social: Percursos, vivências e estratégias em Maracanaú [Dissertação de mestrado, Universidade Estadual do Ceará].

Rodrigues, J. S., Lima, A. F., \& Holanda, R. B. (2018). Identidade, drogas e saúde mental: Narrativas de pessoas em situação de rua. Psicologia: Ciência e Profissão, 38(3), 424-436. https://doi.org/10.1590/1982-37030004912017

Rondon Filho, E. B. (2013). Polícia e minorias: Estigmatização, desvio, discriminação. Dilemas: Revista de Estudos de Conflito e Controle Social, 6(2), 269-293. https://revistas.ufrj.br/index.php/dilemas/article/view/7427

Rosa, A. S., \& Brêtas, A. C. P. (2015) A violência na vida de mulheres em situação de rua na cidade de São Paulo, Brasil. Interface, 19(3), 275-285. https:// doi.org/10.1590/1807-57622014.0221

Rosa, C. M. M., Bezerra, E. M. R., \&Vieira, M. A. A. C. (1992). População em situação de rua: Quemé, como vive, como é vista. Editora Hucitec.

Saffioti, H. I. B. (2015) Gênero, patriarcado, violência. Fundação Perseu Abramo.

Sarmento, C. S. (2020). "Por que não podemos ser mães?”: Tecnologias de governo, maternidade e mulheres com trajetória de rua [Dissertação de mestrado, Universidade Federal do Rio Grande do Sul]. Repositório Digital Lume UFRGS. http://hdl.handle.net/10183/212984

Schilling, F., \& Miyashiro, S. G. (2008) Como incluir? O debate sobre o preconceito e o estigma na atualidade. Educação e Pesquisa, 34(2), 243-254. https://doi.org/10.1590/S1517-97022008000200003 
Sicari, A. A., \& Zanella, A. V. (2018). Pessoas em situação de rua no Brasil: Revisão sistemática. Psicologia: Ciência e Profissão, 38(4), 243-254. https://doi.org/10.1590/1982-3703003292017

Spiassi, A. L. (2016). Violência como fator de vulnerabilidade para a saúde de mulheres usuárias de drogas do centro do município de São Paulo [Tese de doutorado, Universidade de São Paulo]. Biblioteca Digital USP. https://doi. org/10.11606/T.5.2016.tde-08092016-094640

Zavaleta, D. (2007). The ability to go about without shame: A proposal for internationally comparable indicators of shame and humiliation. OPHI Working Paper, (3). https://ophi.org.uk/working-paper-number-03/

\section{Andréa Ferreira Lima Esmeraldo}

Doutoranda em Psicologia pela Universidade Federal do Ceará (UFC), Fortaleza - CE, Brasil. Psicóloga atuante na política pública de Assistência Social.

E-mail: andreaesmeraldopsi@gmail.com

(1) https://orcid.org/0000-0003-2010-0773

\section{Verônica Morais Ximenes}

ProfessoraTitular do Programa dePós-Graduação em Psicologia da UniversidadeFederaldo Ceará (UFC). Doutorado em Psicologia pela Universidade de Barcelona, Espanha. Pós-Doutorado em Psicologia pela Universidade Federal do Rio Grande do Sul (UFRGS). Bolsista Produtividade do CNPq

E-mail: vemorais@yahoo.com.br

(1) https://orcid.org/0000-0003-3564-8555

Endereço para envio de correspondência:

Universidade Federal do Ceará, Departamento de Psicologia. Avenida da Universidade, 2762, Benfica.

CEP: 60020-181. Fortaleza - CE. Brasil.

Recebido 23/03/2020

Aceito $14 / 07 / 2021$

Received $03 / 23 / 2020$

Approved 07/14/2021

Recibido 23/03/2020

Aceptado 14/07/2021

Como citar: Esmeraldo, A. F. L., \& Ximenes, V. M. (2022). Mulheres em situação de rua: Implicações psicossociais de estigmas e preconceitos. Psicologia: Ciência e Profissão, 42, 1-15. https://doi.org/10.1590/1982-3703003235503

How to cite: Esmeraldo, A. F. L., \& Ximenes, V. M. (2022). Mujeres en situación de calle: Implicaciones psicosociales de estigmas y prejuicios. Psicologia: Ciência e Profissão, 42, 1-15. https://doi.org/10.1590/1982-3703003235503

Cómo citar: Esmeraldo, A. F. L., \& Ximenes, V. M. (2022). Homeless women: Psychosocial implications of stigmas and prejudices. Psicologia: Ciência e Profissão, 42, 1-15. https://doi.org/10.1590/1982-3703003235503 